\title{
Do Estrogen and Alendronate Improve Metaphyseal Fracture Healing When Applied as Osteoporosis Prophylaxis?
}

\author{
Leila Kolios • Ann Kristin Hoerster • Stephan Sehmisch • Marie Christin Malcherek • \\ Thomas Rack • Mohammed Tezval • Dana Seidlova-Wuttke • Wolfgang Wuttke • \\ Klaus Michael Stuermer • Ewa Klara Stuermer
}

Received: 23 March 2009/Accepted: 2 October 2009/Published online: 1 December 2009

(c) The Author(s) 2009. This article is published with open access at Springerlink.com

\begin{abstract}
Osteoporosis is accompanied by predominantly metaphyseal fractures with a delayed and qualitatively reduced healing process. This study addressed the question of whether fracture healing in the context of osteoporosis prophylaxis is improved with estrogen (E) or alendronate (ALN). Thirty-six ovariectomized and 12 sham-operated 12-week-old rats received soy-free (osteoporotic C, sham), E-, or ALN- supplemented diets. After 10 weeks, a metaphyseal tibia osteotomy and standardized T-plate fixation were performed. After a 5-week healing process, the fracture callus was evaluated qualitatively by biomechanical bending test and quantitatively in microradiographic sections. The time course of callus formation was examined using fluorochrome-labeled histological sections. Administration of $\mathrm{E}$ improved the biomechanical properties of callus (stiffness [N/mm]: sham: $110.2 \pm 76.07, \mathrm{C}$ : $41.28 \pm 33.70$, E: $85.72 \pm 47.24$, ALN: $72.07 \pm 34.68)$. The resistance to microfracturing seen in E-treated animals was significantly enhanced and even superior to sham (yield load [N] sham: $27.44 \pm 9.72, \mathrm{C}: 21.04 \pm 12.47, \mathrm{E}$ : $42.85 \pm 13.74^{\Delta}$, ALN: $\left.25.28 \pm 6.4\right)(* P<0.05$ vs. sham
\end{abstract}

L. Kolios $(\bowtie) \cdot$ A. K. Hoerster · S. Sehmisch .

M. C. Malcherek · T. Rack - M. Tezval .

K. M. Stuermer · E. K. Stuermer

Department of Trauma and Reconstructive Surgery,

Georg-August-University of Goettingen, Robert-Koch-Str. 40,

37075 Goettingen, Germany

e-mail: leilakolios@freenet.de

D. Seidlova-Wuttke $\cdot$ W. Wuttke

Department of Clinical and Experimental Endocrinology,

Georg-August-University of Goettingen, Robert-Koch-Str. 40,

37075 Goettingen, Germany group, ${ }^{\Delta} P<0.05$ vs. $\mathrm{C}$ group, ${ }^{\bullet} P<0.05$ vs. E group). Trabecular bone in particular was improved, indicating the presence of physiological endosteal bridging (Tr.Dn [\%] sham: $10.53 \pm 18.9, \mathrm{C}: 1.01 \pm 0.14, \mathrm{E}: 24.13 \pm 34.09^{\Delta}$, ALN: $3.99 \pm 8.3^{\circ}$ ). ALN did not help bone healing, as shown by mechanical tests. Compared to the $\mathrm{C}$ group, statistically, ALN did not show worse properties. The induction of callus formation under ALN treatment was slightly delayed (Tt.Cl $\left[\mathrm{mm}^{2}\right]$ sham: $3.68 \pm 0.66, \mathrm{C}$ : $3.44 \pm 0.42$, E: $3.69 \pm 0.58$, ALN: $3.06 \pm 0.56$ ). Osteoporotic metaphyseal fracture healing was qualitatively and quantitatively improved by $\mathrm{E}$ prophylaxis. The process of fracture healing occurred nearly physiologically (shamlike). Notably, ALN hardly improved metaphyseal callus properties when assessed as osteoporosis prophylaxis, but to a lesser extent than $\mathrm{E}$.

Keywords Alendronate - Bisphosphonate - Estrogen · Metaphyseal fracture healing $\cdot$ Osteoporosis

Life expectancy has recently increased, resulting in changing population demographics. As the population ages, osteoporosis is becoming one of the most prominent worldwide health problems. Menopause involves hormonal changes that increase bone turnover and distort the balance between bone formation and bone resorption [1]. Hormone deficiency impairs cancellous metaphyseal bone, which reduces bone mineral density (BMD) in humans and animals [2-4]. Within the metaphysis, the trabecular structure degrades. Bone loss occurs in the diaphyseal bone as well, but to a lesser extent [5]. The mechanical strength of cortical bone is preserved as a result of periosteal apposition [4]. Therefore, long bones are more often predisposed to osteoporotic fractures at the 
metaphysis rather than at the diaphysis [3, 6]. The lifetime risk in the United States for a hip, spine, or forearm fracture at the age of 50 years has been estimated to be $40 \%$ in women and $13 \%$ in men [7]; overall reduction in survival due to osteoporotic hip fractures is approximately $15 \%$ [8]. In osteoporotic organisms, the fracture healing process is delayed and poor in quality $[9,10]$. Especially in humans, postmenopausal osteoporosis negatively affects the fracture healing process [11], and the recovery of functional competence is delayed [12].

Treatment with estrogen (17- $\beta$-E), selective estrogen receptor modulators (SERMs), or bisphosphonates has been shown to improve postmenopausal osteoporotic bone [13]. Estrogen (E) therapy, such as hormone replacement therapy (HRT), was aborted during the Women's Health Initiative hormone trial because of the increased incidence of breast cancer, thromboembolic events and stroke, and cardiovascular disease [14]. However, recently, more detailed analyses have shown that HRT can be beneficial without increasing the risk of these conditions when initiated in early menopausal women. Additionally, selection of the appropriate dose and application method can also reduce the risks associated with HRT [15].

Bisphosphonate alendronate (ALN) is applied as an antiresorptive treatment that induces the formation of a large callus with high bone mineral content. Such structures have, until now, been examined mostly in diaphyseal fractures [16]. As an osteoclast inhibitor, it delays callus remodeling, so that diaphyseal fractures are healed with large amounts of imperfect, woven bone material $[16,17]$. Nitrogen-containing ALN inhibits osteoclastmediated bone resorption through inhibition of the mevalonate pathway and impairment of intracellular vesicle transport. Its effects are not related to a decrease in osteoclast number, and apoptosis occurs only as a secondary phenomenon [18]. Bisphosphonates are widely recognized as effective agents to increase bone mass and reduce fracture risk in primary and secondary osteoporosis [19-22]. Notably, bisphosphonates enhance BMD in the affected extremities during fracture healing [23, 24]. However, a decrease in tissue heterogeneity, characterized by alterations in the distribution of BMD, mineral crystal composition, and collagen maturity, has been observed under ALN treatment, and this could affect bone strength [25].

In the present study, E and ALN were applied in ovariectomized rats for osteoporosis prophylaxis and tested for their effects on the fracture healing process. The metaphyseal fracture model was chosen because osteoporotic fractures affect mainly metaphyseal cancellous bone. The study design allowed us to examine the osteoporotic fractures that occurred during osteoporosis prophylaxis with $\mathrm{E}$ and ALN.

\section{Materials and Methods}

Animals and Treatment Groups

Thirty-six 12-week-old female Sprague Dawley rats (Winkelmann, Borken, Germany) were ovariectomized, and 12 control rats underwent sham operation under xylazine (Rompun, Bayer Health Care) and ketamine (Ketanest S, Pfizer Pharma) $(3.5 \mathrm{v} / \mathrm{v}, 1 \mathrm{ml} / \mathrm{kg}$ ) anesthesia. After surgery, ovariectomized rats were divided in three groups, each containing 12 animals. The first group (C) and the sham-operated group were fed phytoestrogen-free pelleted food (Ssniff SM R/M, 10-mm pellets; Ssniff Spezialitäten $\mathrm{GmbH}$, Soest, Germany). The third group (E) received phytoestrogen-free food supplemented with 17- $\beta$ estradiol (Sigma Medical, Apeldoorn, The Netherlands). The average daily intake was $0.086 \mathrm{~g}$. In the fourth group, phytoestrogen-free food was supplemented with ALN $(10 \mathrm{mg} / \mathrm{kg}$, Merck \& Co., Whitehouse Station, NJ). This group was subjected to an average intake of $0.17 \mathrm{mg} / \mathrm{d}$. The substances were applied in established oral doses [17, 26, 27]. After 10 weeks, during which the ovariectomized animals developed osteoporosis [28], all animals underwent a newly developed bilateral proximal metaphyseal osteotomy and osteosynthesis, which was performed with a five-hole T-shaped titanium plate (XS 57-05140, Stryker Trauma, Selzach, Switzerland) bridging technique [29]. The treatment with specific diets was continued up to 35 days.

The animal study protocol was approved by the local regional government and conformed to German animal protection laws (District Government of Braunschweig, permission from 12/05/03, Az: 509.42502/01-53.03).

\section{Intravital Fluorochrome Labeling}

To visualize the location, amount, and time course of newly built bone tissue, we subcutaneously injected fluorochrome stains, which bind competitively to the calcium on the surface of hydroxylapatite in newly built bone (Merck, Darmstadt, Germany) [30]. The stains used included xylenol (orange, $90 \mathrm{mg} / \mathrm{kg}$ ) on day 13 , calcein (green, $10 \mathrm{mg} / \mathrm{kg}$ ) on day 18 , alizarin (red, $30 \mathrm{mg} / \mathrm{kg}$ ) on days 24 and 26, and tetracycline (yellow, $25 \mathrm{mg} / \mathrm{kg}$ ) on day 35 . The additional dose of alizarin red was provided on day 26 to intensify the color.

Preparation of the Tibiae

The animals were decapitated while under deep $\mathrm{CO}_{2}$ anesthesia on day 35. Tibiae were prepared; the skin, muscles, and tendons of the lower leg were removed accurately. Exarticulation of the tibia-fibula complex in the 

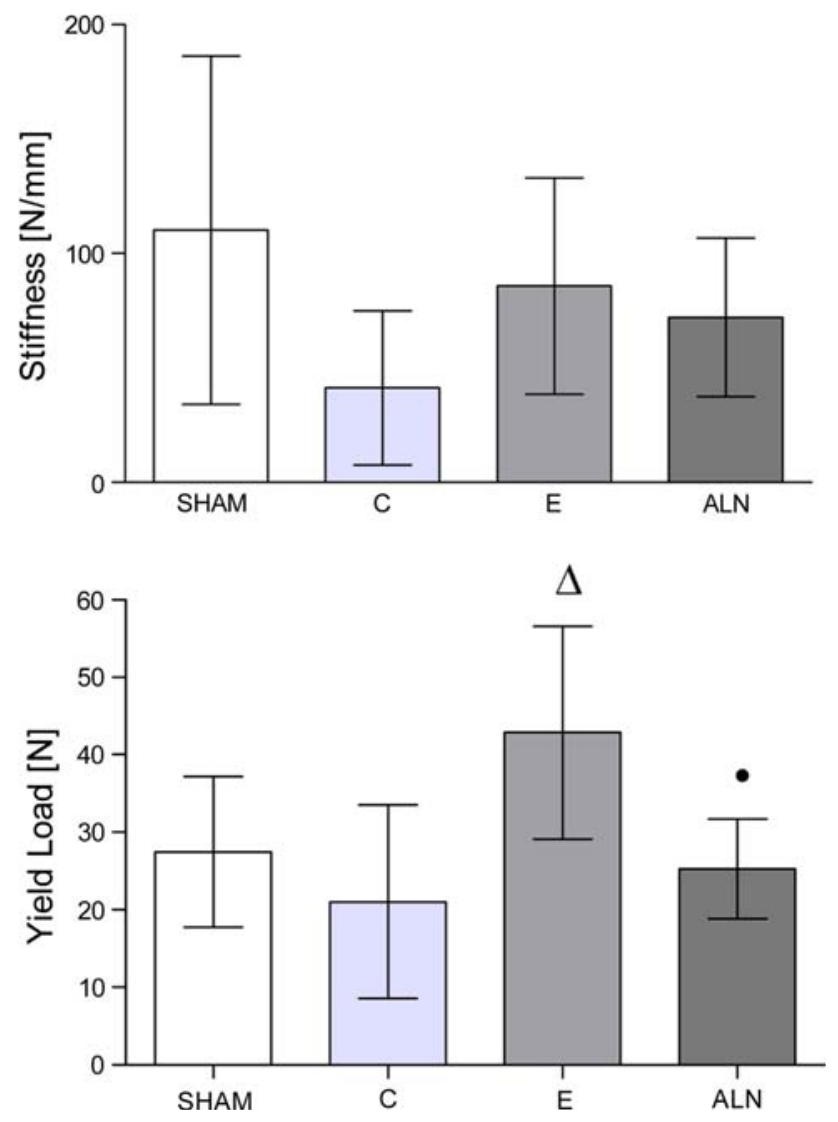

Fig. 1 Biomechanical testing of callus formation. Stiffness was not significantly enhanced in the estrogen (E)-treated group; changes in the alendronate (ALN)-treated group did not reach sham values. Yield load in the E group was significantly improved compared to the osteoporotic C (C) group, and superior to sham group. The ALN group was slightly enhanced compared to C. $P$ values of $<0.05$ were considered to be significant ( ${ }^{*} P<0.05$ vs. sham, ${ }^{\Delta} P<0.05$ vs. C, - $P<0.05$ vs. E)

knee and ankle joint followed. The plate and screws were removed. Tibiae were immediately stored in plastic tubes at $-20^{\circ} \mathrm{C}$ until further analysis.

\section{Radiographic Evaluation and Mechanical Testing}

Microfocus radiographs were taken in the anteroposterior and mediolateral views, and fracture healing of each osteosynthesis was evaluated in a blinded manner. In particular, the position of the implants, accidental fracturing of the fibula, and axial deviation were examined.

A standardized three-point bending and breaking test device (Zwick Software, Bensheim, Germany) was used to examine the biomechanical properties of the callus area, including stiffness (S) and yield load, as previously described [31]. The stamp of the test device was driven down with a speed of feet motion of $50 \mathrm{~mm} / \mathrm{min}$. The force (N) was plotted against the distance of tibial bending $(\mathrm{mm})$.
This curve shows a linear progression in the first phase, which represents the stiffness of the bone. In the second part of the curve, the magnitude of this positive slope declines; elasticity changes to irreversible plastic deformation. The onset of curve declination is the force of first microfracturing (yield load).

\section{Preparation for Microscopy and Microradiography}

Tibiae were defatted and embedded in methylmethacrylate. By means of a standardized cutting technique, the three central sections of the metaphyseal fracture region from the level of the eminentia intercondylaris were used for microscopic evaluation and microradiographed for quantitative analyses. Microradiography was performed as previously described [32]. A light microscope (Leitz DMRXE, Leica, Bensheim, Germany) with an I3 filter system (excitation filter $450-490 \mathrm{~nm}$, dichronic mirror $510 \mathrm{~nm}$, suppression filter $515 \mathrm{~nm}$ ) was used. The different fluorochrome-labeled areas were evaluated with the transmitted and incident light objective (PL Fluotar 10/0.30). Histological sections and microradiographic images were assessed with a digital camera (Leica DC200) and the Quantimet digital image processing system (Leica DMRXE, Bensheim, Germany).

\section{Evaluation and Statistics}

In the microradiographs, callus density (amount of calcified tissue per $\mathrm{mm}^{2} /$ callus area) and the callus width (mean width measured by 10 parallel lines placed perpendicularly to cortical bone) as well as cortical structure (density and width) and trabecular bone parameters (density, width, and number of nodes) were determined digitally. Data are shown as the means of three microradiographic sections (Fig. 5). For the intravital fluorochrome-labeled histological sections, the same areas were evaluated to determine the amount of bound calcein (green), alizarin (red), and tetracycline (yellow) labeling by the Quantimet digital image processing system (Fig. 5) [32]. It was not possible to visually distinguish the xylenol (orange) because only a small island of xylenol-labeled bone could be found, and this was surrounded by intensely green, calcein-labeled bone. In addition, the total callus area was calculated. The ASBMR Nomenclature Committee [33] was followed for all abbreviations.

For statistical analysis of the data, the mean values and standard deviations for each parameter were calculated. Differences between the four tested groups were assessed by one-way analysis of variance and Tukey-Kramer post hoc tests (Prism, GraphPad, San Diego, CA). $P$ values of $<0.05$ were considered to be significant. 
Table 1 Quantitative evaluation of microradiographic sections of the tibial callus formation in osteoporotic rats

\begin{tabular}{|c|c|c|c|c|c|c|c|c|}
\hline \multirow[t]{2}{*}{ Microradiography } & \multicolumn{2}{|l|}{ Sham } & \multicolumn{2}{|l|}{$\mathrm{C}$} & \multicolumn{2}{|l|}{$\mathrm{E}$} & \multicolumn{2}{|l|}{ ALN } \\
\hline & Mean & SD & Mean & SD & Mean & SD & Mean & SD \\
\hline Cortical width ventromedial (Ct.Wi.v) (mm) & 0.29 & \pm 0.14 & 0.32 & \pm 0.1 & 0.33 & \pm 0.11 & 0.34 & \pm 0.12 \\
\hline Cortical width dorsal (Ct.Wi.d) (mm) & 0.37 & \pm 0.09 & 0.31 & \pm 0.1 & $0.3^{*}$ & \pm 0.08 & $0.29 *$ & \pm 0.06 \\
\hline Cortical density ventromedial (Ct.Wi.v) (\%) & 89.28 & \pm 3.89 & 98.46 & \pm 1.31 & 99.13 & \pm 1.07 & 98.11 & \pm 2.07 \\
\hline Cortical density dorsal (Ct.Wi.d) (\%) & 98.33 & \pm 2.05 & 97.42 & \pm 2.1 & 98.14 & \pm 2.075 & 97.41 & \pm 2.85 \\
\hline Callus width ventromedial (Cl.Wi.v) (mm) & 0.55 & \pm 0.28 & 0.58 & \pm 0.29 & 0.51 & \pm 0.24 & 0.59 & \pm 0.29 \\
\hline Callus width dorsal (Cl.Wi.d) (mm) & 0.44 & \pm 0.34 & 0.44 & \pm 0.24 & 0.39 & \pm 0.16 & 0.27 & \pm 0.17 \\
\hline Callus density dorsal (Cl.Dn.d) (\%) & 63.91 & \pm 29.75 & 55.74 & \pm 28.86 & 69.91 & \pm 18.85 & 55.95 & \pm 23.61 \\
\hline Trabecular width $(\mathrm{Tr} . \mathrm{Wi})(\mu \mathrm{m})$ & 2.11 & \pm 1.84 & 0.97 & \pm 0.07 & $3.07^{\Delta}$ & \pm 2.9 & $1.5^{\circ}$ & \pm 1.21 \\
\hline
\end{tabular}

$C$ osteoporotic C, $E$ estrogen, $A L N$ alendronate

${ }^{\mathrm{a}}$ Average value $\pm \mathrm{SD}$ of the mean. $P$ values of $<0.05$ were considered to be significant $\left(* P<0.05\right.$ vs. sham group, ${ }^{\Delta} P<0.05$ vs. C group, $\bullet P<0.05$ vs. E group)

Fig. 2 Quantitative evaluation of microradiographic sections. Trabecular structure was significantly enhanced in the estrogen (E)-treated group compared to the osteoporotic $\mathrm{C}$ (C) group, surpassing levels observed in the sham group. Alendronate (ALN) was slightly improved compared to C. Callus density was enhanced under $\mathrm{E}$ treatment and less under ALN supplementation. $P$ values of $<0.05$ were considered to be significant $(* P<0.05$ vs. sham, ${ }^{\Delta} P<0.05$ vs. C, - $P<0.05$ vs. E)
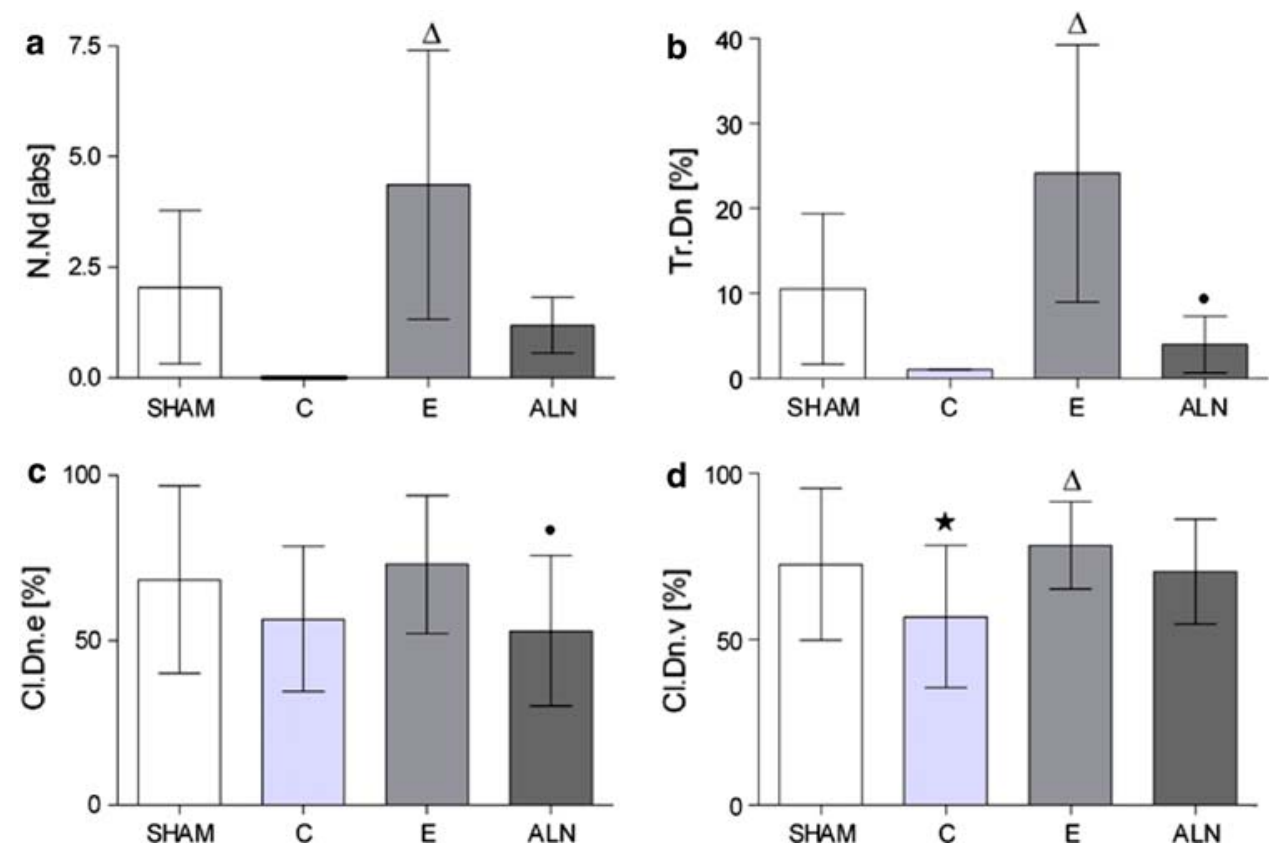

\section{Results}

\section{Body Weight}

After ovariectomy, body weight increased significantly in the $\mathrm{C}$ and ALN groups compared to the sham and $\mathrm{E}$ groups. At the time of osteotomy body weight $(\mathrm{g})$ was: sham, $276.5 \pm 19.2 ; \quad$ C,$\quad 343.3 \pm 23.89^{*} ; \quad$ E， $255.5 \pm 20.46$; ALN, $341.4 \pm 11.98 *$ (*P<0.05 vs. sham group). In the second part of the trial, after the osteotomy procedure, no further changes in body weight were observed.

\section{Radiographic Evaluation}

The tibial osteotomies of all 48 rats healed adequately, without implant loosening. In six rats (two each in the sham, C, and E groups), accidental fracturing of the fibula occurred (probably during internal fixation). Tibiae healed with axial deviation of more than 30 degrees and more visible callus formation. This biomechanical factor confounded the fracture healing process, interfering with the effects of the administered test substances. Thus, these animals were excluded from the analyses.

\section{Biomechanical Testing}

The yield load after E treatment was significantly enhanced compared to the control group and was superior to that observed in the sham group. After ALN treatment, S and yield load were slightly but not significantly improved compared to levels observed in the $\mathrm{C}$ group. However, yield load was significantly lower than in the E group. The 
Table 2 Time-dependent quantitative analysis of intravital fluorochrome labeling with calcein green (CG, day 18), alizarin red (AK, days 24 and 26), and tetracycline (TC, day 35$)^{\mathrm{a}}$

\begin{tabular}{|c|c|c|c|c|c|c|c|c|}
\hline \multirow[t]{2}{*}{ Fluochrome labeling } & \multicolumn{2}{|l|}{ Sham } & \multicolumn{2}{|l|}{$\mathrm{C}$} & \multicolumn{2}{|l|}{$\mathrm{E}$} & \multicolumn{2}{|l|}{ ALN } \\
\hline & Mean & SD & Mean & SD & Mean & SD & Mean & SD \\
\hline Total callus ventromedial (Tt.Cl.v) $\left(\mathrm{mm}^{2}\right)$ & 0.95 & \pm 0.53 & 0.71 & \pm 0.35 & 1.01 & \pm 0.45 & $0.61^{\bullet}$ & \pm 0.39 \\
\hline CG callus area ventromedial (Cl.Ar.v) $\left(\mathrm{mm}^{2}\right)$ & 0.25 & \pm 0.26 & 0.16 & \pm 0.12 & $0.39^{\Delta}$ & \pm 0.28 & $0.14^{\bullet}$ & \pm 0.17 \\
\hline AK callus area ventromedial (Cl.Ar.v) $\left(\mathrm{mm}^{2}\right)$ & 0.09 & \pm 0.11 & 0.06 & \pm 0.05 & 0.1 & \pm 0.07 & 0.1 & \pm 0.09 \\
\hline TC callus area ventromedial (Cl.Ar.v) $\left(\mathrm{mm}^{2}\right)$ & 0.27 & \pm 0.27 & 0.13 & \pm 0.12 & 0.14 & \pm 0.14 & $0.11 *$ & \pm 0.11 \\
\hline Total callus dorsal (Tt.Cl.d) $\left(\mathrm{mm}^{2}\right)$ & 1.61 & \pm 0.74 & 1.52 & \pm 0.1 & 1.4 & \pm 0.56 & 1.3 & \pm 0.76 \\
\hline CG callus area dorsal (Cl.Ar.d) $\left(\mathrm{mm}^{2}\right)$ & 0.5 & \pm 0.21 & 0.43 & \pm 0.39 & 0.54 & \pm 0.23 & 0.52 & \pm 0.37 \\
\hline AK callus area dorsal (Cl.Ar.d) $\left(\mathrm{mm}^{2}\right)$ & 0.21 & \pm 0.27 & 0.17 & \pm 0.2 & 0.11 & \pm 0.06 & 0.16 & \pm 0.11 \\
\hline TC callus area dorsal (Cl.Ar.d) $\left(\mathrm{mm}^{2}\right)$ & 0.41 & \pm 0.29 & 0.22 & \pm 0.23 & 0.33 & \pm 0.38 & 0.2 & \pm 0.23 \\
\hline Total callus endosteal (Tt.Cl.e) $\left(\mathrm{mm}^{2}\right)$ & 1.12 & \pm 0.7 & 1.21 & \pm 0.8 & 1.28 & \pm 0.73 & 1.15 & \pm 0.52 \\
\hline CG callus area endosteal (Cl.Ar.e) $\left(\mathrm{mm}^{2}\right)$ & 0.35 & \pm 0.29 & 0.14 & \pm 0.15 & 0.34 & \pm 0.23 & $0.35^{\Delta}$ & \pm 0.26 \\
\hline AK callus area endosteal (Cl.Ar.e) $\left(\mathrm{mm}^{2}\right)$ & 0.09 & \pm 0.08 & 0.14 & \pm 0.12 & 0.2 & \pm 0.16 & 0.2 & \pm 0.16 \\
\hline TC callus area endosteal (Cl.Ar.e) $\left(\mathrm{mm}^{2}\right)$ & 0.34 & \pm 0.36 & 0.41 & \pm 0.26 & 0.3 & \pm 0.32 & 0.2 & \pm 0.22 \\
\hline
\end{tabular}

$C$ osteoporotic C, $E$ estrogen, $A L N$ alendronate

${ }^{\mathrm{a}}$ Average value $\pm \mathrm{SD}$ of the mean. $P$ values of $<0.05$ were considered to be significant $\left(* P<0.05\right.$ vs. sham group, ${ }^{\Delta} P<0.05$ vs. C group, - $P<0.05$ vs. E group)

stiffness of the three ovariectomized groups was less than that of the sham group, but this trend was not significant (Fig. 1).

\section{Microradiographic Evaluation}

Ventromedial callus width (Cl.Wi.v) did not differ significantly between the groups. Its density (Cl.Dn.v) was improved in the E-treated group $(P<0.05$ vs. $\mathrm{C})$ and did not differ from values observed in the sham group. Dorsal callus width (Cl.Wi.d) in the ALN group was lower compared to that in other groups; however, this trend was not significant. Although the differences were not significant, the dorsal callus density (Cl.Dn.d) was again low in ALN and C, compared to $\mathrm{E}$, while group $\mathrm{E}$ reached values similar to that of the sham group. The $\mathrm{E}$ enhanced the endosteal callus density (Cl.Dn.e, $P<0.05$ vs. ALN). The average trabecular width (Tr.Wi) and trabecular density (Tr.Dn) were significantly greater after E treatment, compared to the ALN and osteoporotic C groups. The number of nodes (N.Nd) was significantly enhanced in the $\mathrm{E}$ group compared to the osteoporotic $\mathrm{C}$ group, while ALN levels were slightly higher than C levels. The ventromedial cortical width (Ct.Wi.v) and density (Ct.Dn.v) showed no significant differences (Table 1). The dorsal cortical width (Ct.Wi.d) was significantly thinner in the E and ALN groups, while the dorsal density (Ct.Dn.d) was comparable in all groups (Fig. 2; Table 1).

\section{Evaluation of Intravital Fluorochrome Labeling}

On the basis of evaluation of the fluorochrome-labeled tibia sections, E treatment most supported endosteal and dorsal callus formation (Tt.Cl.d, e, Table 2). The E induced ventromedial callus formation (Cl.Ar.v) as well; values were similar to those observed in the sham group. ALN induced significantly less callus formation than was seen in the E group (Table 2).

During the early period of fracture healing, marked by calcein green (CG), the E group demonstrated significantly more ventromedial callus deposition (Cl.Ar.v) (Table 2) compared to the C and ALN groups. The early stage of endosteal callus building (CG Cl.Ar.e) was significantly improved by ALN compared to C (Table 2), although ALN had no effect on ventromedial or dorsal callus formation. In the next period of the fracture healing process, labeled by alizarin red, a smaller amount of callus was formed compared to the CG-labeled early period. Endosteal (alizarin red Cl.Ar.e) callus formation was influenced by $\mathrm{E}$ and ALN, but the differences compared to $\mathrm{C}$ were not significant. In the late fracture healing phase, labeled by tetracycline, whole callus formation was enhanced compared to the alizarin redlabeled period, but did not reach the values of the earliest period (Table 2). Comparing the three phases among all groups (Figs. 3, 4), there was a reduction of callus building in the second alizarin red-labeled period in ventromedial and dorsal areas $(P<0.05$ vs. CG phase). 

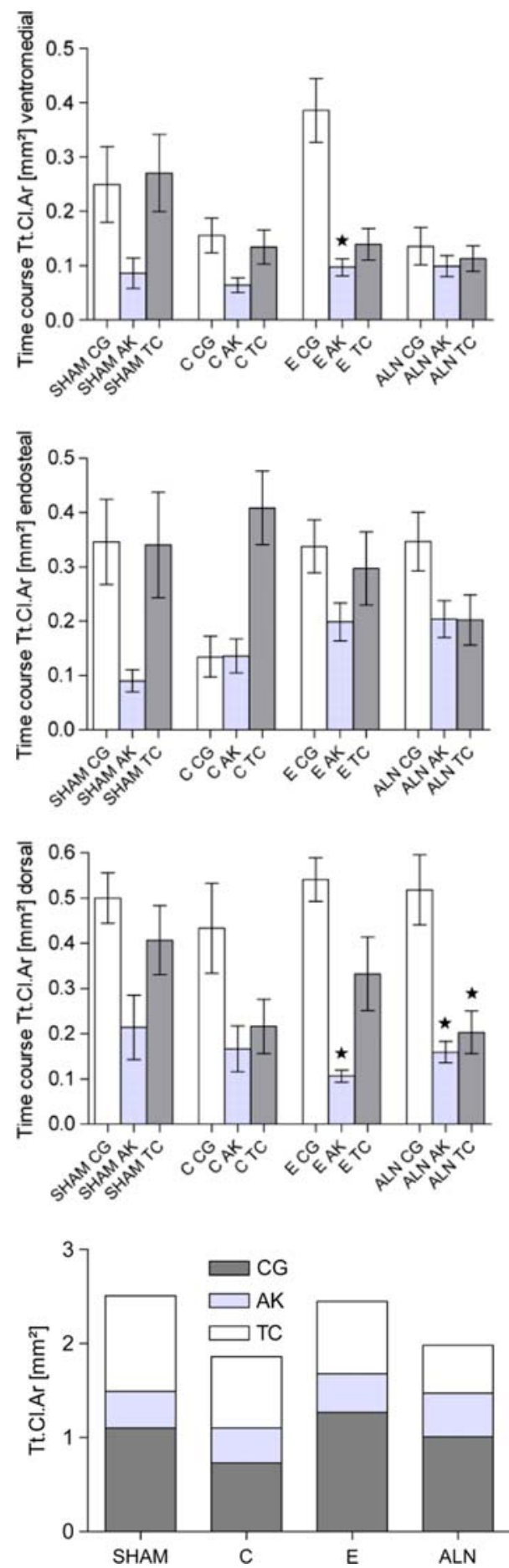

Fig. 3 Intravital fluorochrome labeling. Most of the callus was created during the early, calcein green (CG)-labeled period in endosteal and dorsal regions. $P$ values of $<0.05$ were considered to be significant $(*$ value differs significantly from CG area of same group; ${ }^{\Delta}$ value differs significantly from alizarin red area of same group). The last chart presents the total callus for all stained periods

The time course of dorsal callus-building in the ALN group was significantly reduced during the alizarin red and tetracycline phases compared to the CG period.

\section{Discussion}

Osteoporosis is a major health problem and is accompanied by skeletal fragility and increased fracture risk, especially metaphyseal fractures [3]. The healing of postmenopausal osteoporotic fractures is delayed and quantitatively reduced compared to the rates in normal subjects [9-12, 34]. Thus, treatments that improve the osteoporotic fracture healing process are needed.

Previous experimental studies on fracture healing in osteoporosis have, for the most part, examined the diaphyseal femur [16, 35] or tibia [36]. Studies addressing metaphyseal bone healing have been performed in rats as a pullout trial [37], in sheep using partial osteotomy [6], and in rabbits using defect healing [38], or in the context of varying biomechanical stability [39]. Research on fracture healing in osteoporosis should be performed predominantly at the metaphyseal bone because osteoporosis most strongly affects the metaphyseal cancellous bone [2, 6, 28]. Additionally, diaphyseal bone heals primarily with periosteal callus formation, while metaphyseal bone heals predominantly endosteally [29]. Therefore, a metaphyseal osteotomy model was developed [29] in a well-established rat model of osteoporosis.

The $\mathrm{E}$ treatment as an osteoporosis prophylaxis led to enhanced resistance (yield load, $P<0.05$ vs. C) and elasticity of the callus (Fig. 1). Trabecular microstructure was also improved $(P<0.05$ vs. C) under E treatment (Fig. 2$)$, but this had no positive effect on the surrounding cortical bone (Table 1). Regarding the callus formation rate in dorsal and ventromedial areas, E induced extended callus tissue formation during the first phase of healing, so that the fracture site was stabilized early. With further treatment, less callus building was necessary $(P<0.05$ vs. CG phase, Fig. 3). Endosteally, callus apposition seemed more balanced during all periods, indicating enhancement of the endosteal healing process. Thus, E-supported fracture healing occurred in a physiological manner, as evidenced by the fact that the callus stabilized the bone primarily via endosteal bridging (Fig. 2; Table 1), as is typical for fracture healing in healthy metaphyseal bone [29]. The enhanced callus tissue in the dorsal region also results from the osteotomy design. The ventromedial positioning of the bridging plate and the remaining $0.5-\mathrm{mm}$ osteotomy gap permit micromovements at the dorsal fracture site. This mechanical stimulus positively affects fracture callus formation.

These findings suggest that a short treatment course (during the first weeks after an osteoporotic fracture occurs) might be beneficial in humans. During this limited treatment period, the positive effects on fracture incidence, fracture healing, patient mobility, and rehabilitation could outweigh any potential negative effects associated with long-term E therapy. This observation is in accordance 
Fig. 4 Corresponding microradiographic and fluorescence-labeled sections. Compared to physiological healing in the sham group, callus formation in the osteoporotic C (C) group was enhanced, but unstructured and less dense. Estrogen (E) administration induced less callus formation, but the callus present was very compact and dense, with increased amounts of trabecular structure. The alendronate (ALN) group displayed fewer and unconstrained calluses and trabeculas
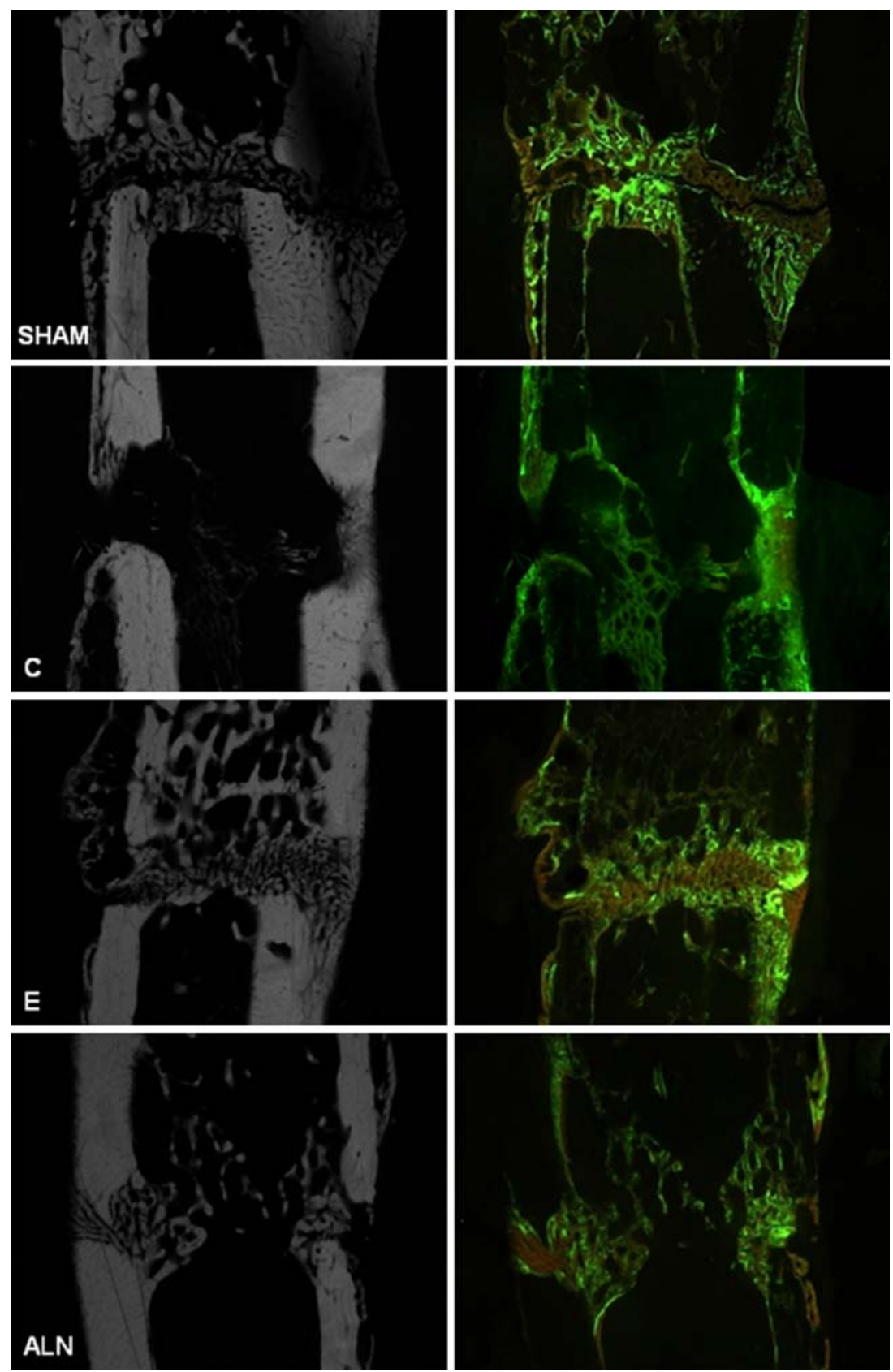

with recent, more detailed analyses of HRT [15]. In particular, it seems that when initiated in early-menopausal women and given at the appropriate dose via the appropriate application method, E therapy can provide many benefits without increasing the risk of certain complications associated with HRT.

Bisphosphonates have been recognized to have positive effects on BMD and fracture incidence in osteoporotic bones. They are considered effective, safe, and well tolerated, and can increase bone mass and reduce fracture risk in primary and secondary osteoporosis [19-22]. In this study, the ALN showed limited ability to improve the quality and quantity of fracture callus tissue.
In the physiological fracture healing process, a continuous remodeling of the first, very elastic, woven bone into lamellar bone takes place, yielding the biomechanical properties of cortical bone. The amount of callus formation was reduced under ALN therapy in comparison to $\mathrm{E}$ and sham groups and slightly improved compared to the $\mathrm{C}$ group. The biomechanical properties of the callus in the ALN group were similar to those observed in untreated osteoporotic rats. We expected extensive callus building during ALN treatment $[16,17]$ as a result of the osteoclast-inhibiting effect as well as the delayed remodeling process, but we did not observe such a trend. A significantly lower mineral apposition rate, bone formation rate, and mineralizing surface in 
Fig. 5 Examples of Quantimetbased evaluation of microradiographic ( $a$ : native picture, $b$ cortical structure, $c$ callus areas, $d$ trabecular structure) and fluorescencelabeled sections ( $a$ native picture, $b$ cortical structure, $c$ calcein green-labeled callus, $d$ alizarin red-labeled callus, $e$ tetracycline-labeled callus, $f$ entire callus area)
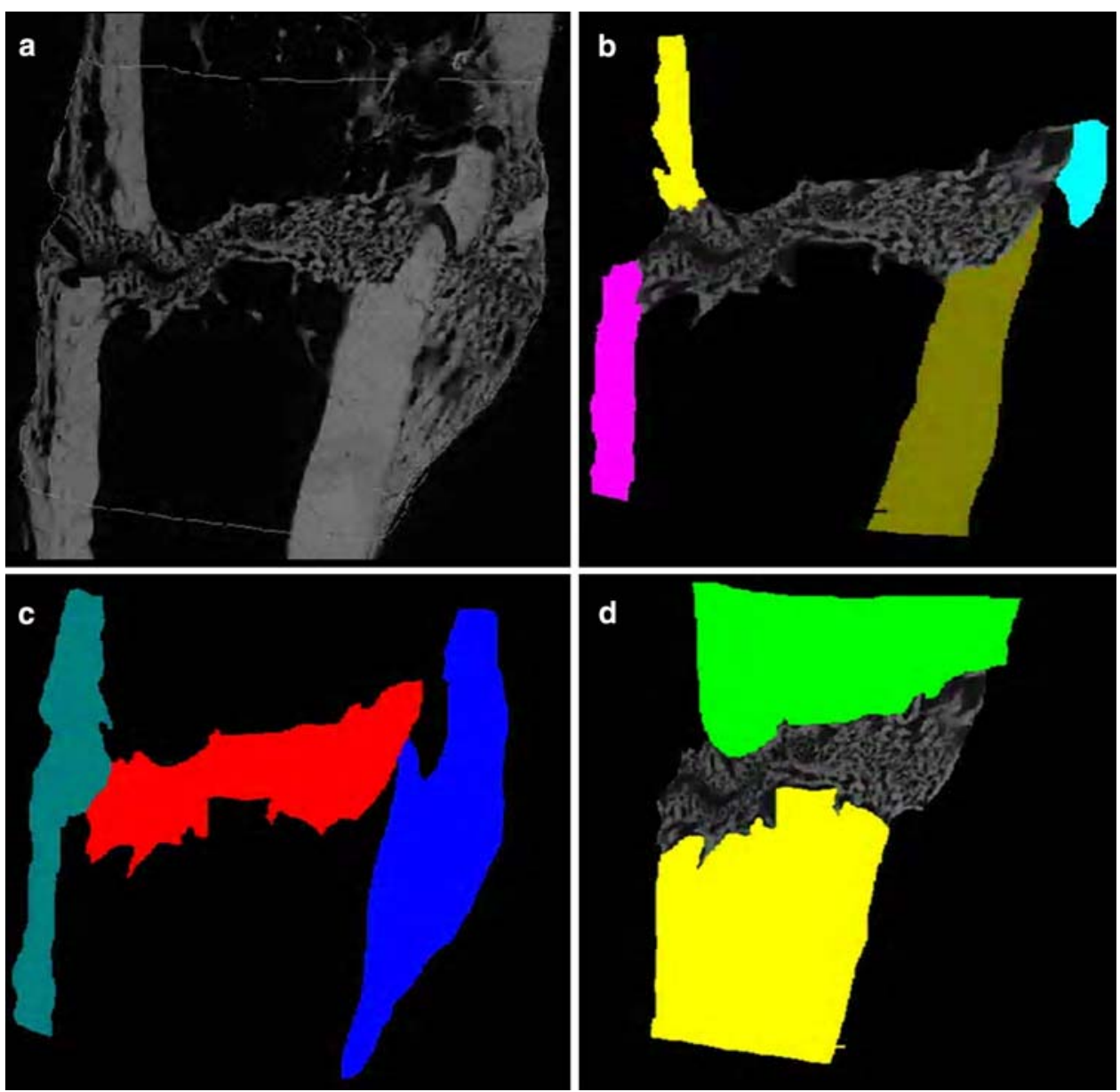

fracture healing under ALN compared to control groups has already been reported [40]. In that study, a prolongation of the natural fracture healing process due to strong suppression of osteoclastic bone resorption is suggested. Other recent studies found high binding affinities of ALN for bone hydroxyapatite, which affects mineral dynamics and cellular function within bone [41]. Additionally, bone strength is affected by the distribution of BMD, mineral crystal composition, and collagen maturity [25]. A reason for the observed callus properties under ALN in this study may be the delayed initiation of callus building as a result of impairment on a cellular level. The extensive callus formation described has been observed in trials with 16 or 26 weeks of fracture healing [16, 17, 40, 42]. The 5-week duration of this study may have been too brief.

One aspect of the metaphyseal cortical bone in the rat tibia must be mentioned: as previously described [29, 43] (Stuermer et al., personal communication), osteoporosis does not seem to influence the metaphyseal cortical bone. Therefore, the investigated substances had no influence on the cortical width or the cortical density (Table 1).

The results of this study are presented bearing in mind the methodological limitations of the work. First, the design of the study focused on short-term application of the substances. The fracture healing and biomechanical values might differ with longer-term E and especially ALN supplementation. In addition, we did not examine all systemic effects, but rather focused on E substitution. Because of the presence of $\mathrm{E}$ in the sham and in the E-treated groups, body weight was significantly lower than in the ALN and the osteoporotic control group. This is a well-known systemic effect of $\mathrm{E}$ [2]. The differences in the body weights may have an influence on the biomechanical properties of bone, but this was not factored into the results. This study analyzed whether ALN and E improve fracture healing in comparison to untreated osteoporotic bone, and whether the treatment could achieve results with the quality and quantity of healthy bone (sham). Therefore, the systemic effects have to be considered in analysis of all results.

We now know about three-dimensional analyses by quantitative computed tomography (QCT) or microfocus computed tomography $(\mu \mathrm{CT})$ but at the time of this work, these methods were not yet available.

In summary, osteoporotic metaphyseal fracture healing is improved by E prophylaxis. The fracture healing process occurs at a nearly physiological level. The widely used and 
Fig. 5 continued
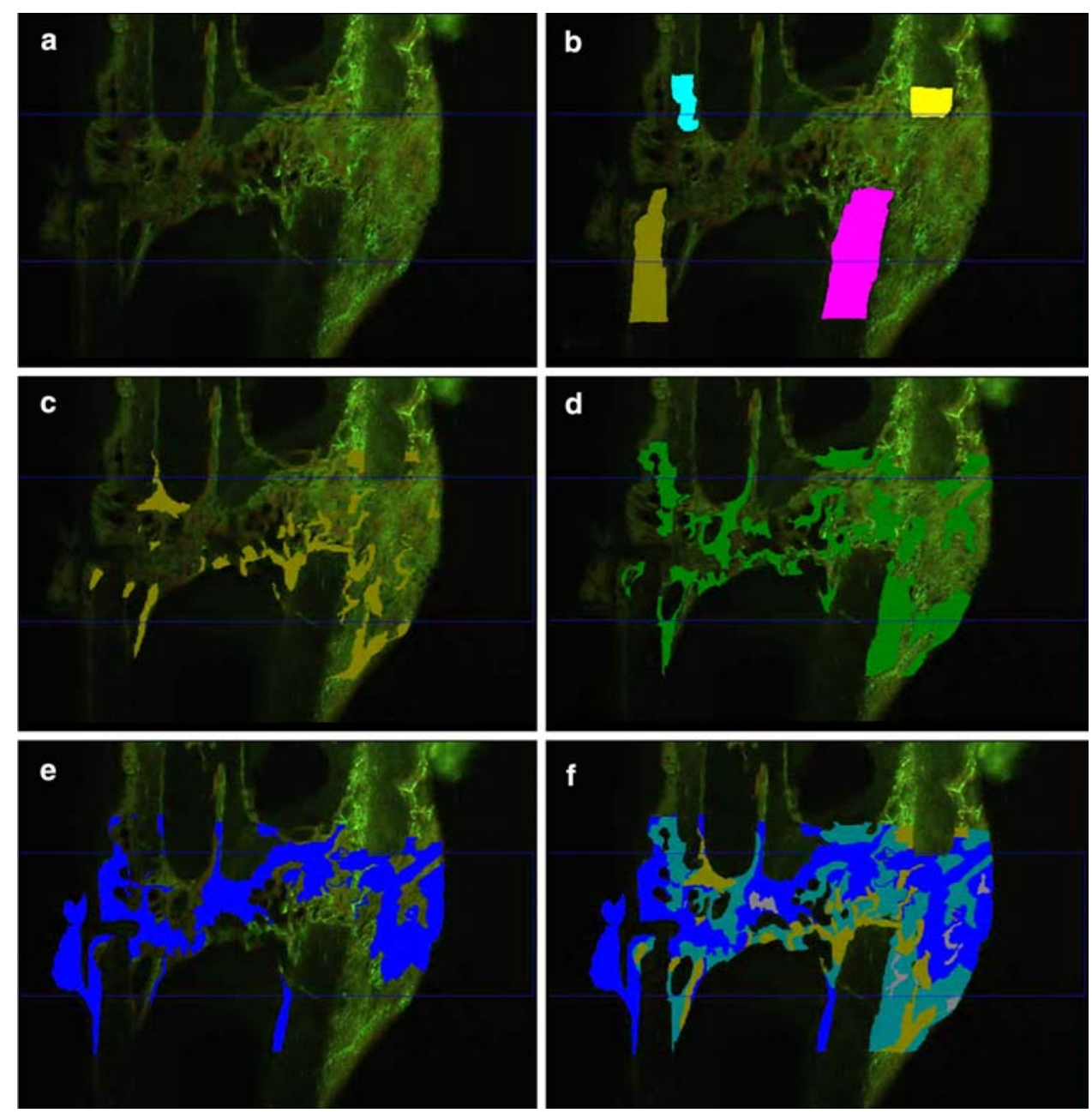

effective antiosteoporotic ALN negligibly improved metaphyseal fracture healing, quantitatively and qualitatively compared to control group, but did not exhibit E-like properties. Finally, the metaphyseal tibial osteotomy model in ovariectomized rats produced reliable results regarding the therapeutic effects of antiosteoporotic substances.

Acknowledgments This work was supported by the DFG (STU 478/2-1). We thank F. Kauer, R. Castro, and A. Witt for their support of the animal trial; Merck \& Co., Whitehouse Station, NJ, for providing us with the test substance ALN, and Stryker Trauma, Selzach, Switzerland, for providing us with implant material.

Open Access This article is distributed under the terms of the Creative Commons Attribution Noncommercial License which permits any noncommercial use, distribution, and reproduction in any medium, provided the original author(s) and source are credited.

\section{References}

1. Savoca S, D'Agosta S, Lombardo G (2007) Evaluation of the hematochemical parameters and bone mineral density of women in physiological menopause treated with hormone replacement therapy with nomegestrol acetate and surgical menopause treated with estrogen replacement. Part II. Minerva Ginecol 59:215-222
2. Thompson DD, Simmons HA, Pirie CM, Ke HZ (1995) FDA guidelines and animal models for osteoporosis. Bone 17:125-133

3. Curtis R, Goldhahn J, Schwyn R, Regazzoni P, Suhm N (2005) Fixation principles in metaphyseal bone-a patent based review. Osteoporos Int 16:54-64

4. Ahlborg HG, Johnell O, Turner CH, Rannevik G, Karlsson MK (2003) Bone loss and bone size after menopause. N Engl J Med 349:327-334

5. Iwaniec UT, Moore K, Rivera MF, Myers SE, Vanegas SM, Wronski TJ (2008) A comparative study of the bone-restorative efficacy of anabolic agents in aged ovariectomized rats. Osteoporos Int 18:351-362

6. Claes L, Veeser A, Göckelmann M, Simon U, Ignatius A (2009) A novel model to study metaphyseal bone healing under defined biomechanical conditions. Arch Orthop Trauma Surg 129:923928

7. Johnell O, Kanis J (2005) Epidemiology of osteoporotic fractures. Osteoporos Int 16:3-7

8. Dennison E, Cooper C (2000) Epidemiology of osteoporotic fractures. Horm Res 54:58-63

9. McCann RM, Colleary G, Geddis C, Clarke SA, Jordan GR, Dickson GR, Marsh D (2008) Effect of osteoporosis on bone mineral density and fracture repair in a rat femoral fracture model. J Orthop Res 26:384-393

10. Hao YL, Zhang G, Wang YS, Qin L, Hung WY, Leung K, Pei FX (2007) Changes of microstructure and mineralized tissue in the middle and late phase of osteoporotic fracture healing in rats. Bone 41:631-638 
11. Augat P, Simon U, Liedert A, Claes L (2005) Mechanics and mechano-biology of fracture healing in normal and osteoporotic bone. Osteoporos Int 16:36-43

12. Barrios C, Brostrom LA, Stark A, Walheim G (1993) Healing complications after internal fixation of trochanteric hip fractures: the prognostic value of osteoporosis. J Orthop Trauma 7:438-442

13. Kanis JA, Burlet N, Cooper C, Delmas PD, Reginster JY, Borgstrom F, Rizzoli R (2008) European guidance for the diagnosis and management of osteoporosis in postmenopausal women. Osteoporos Int 19:399-428

14. Horwitz KB (2008) The year in basic science: update of estrogen plus progestin therapy for menopausal hormone replacement implicating stem cells in the increased breast cancer risk. Mol Endocrinol 22:2743-2750

15. Tarakida A, Higuchi T, Mizunuma H (2007) Evidence of hormone replacement therapy for osteoporosis. Clin Calcium 18: 1434-1441

16. Cao Y, Mori S, Mashiba T, Westmore MS, Ma L, Sato M, Akiyama T, Shi L, Komatsubara S, Miyamoto K, Norimatsu H (2002) Raloxifene, estrogen and alendronate affect the processes of fracture repair differently in ovariectomized rats. J Bone Miner Res 17:2237-2246

17. Cao Y, Mori S, Mashiba T, Kaji Y, Manabe T, Iwata K, Miyamoto K, Komatsubara S, Yamamoto T (2007) 1Alpha, 25dihydroxy-2beta(3-hydroxypropoxy)vitamin D3 (ED-71) suppressed callus modelling but did not interfere with fracture healing in rat femora. Bone 40:132-139

18. Alakangas A, Selander K, Mulari M, Halleen J, Lehenkari P, Mönkkönen J, Salo J, Väänänen K (2001) Alendronate disturbs vesicular trafficking in osteoclasts. Calcif Tissue Int 70:40-47

19. Black DM, Cummings SR, Karpf DB, Cauley JA, Thompson DE, Nevitt MC, Bauer DC, Genant HK, Haskell WL, Marcus R, Ott SM, Torner JC, Quandt SA, Reiss TF, Ensrud KE (1996) Randomised trial of effect of alendronate on risk of fracture in women with existing vertebral fractures: fracture Intervention trial research group. Lancet 348:1535-1541

20. Bone HG, Hosking D, Devogelaer JP, Tucci JR, Emkey RD, Tonino RP, Rodriguez-Portales JA, Downs RW, Gupta J, Santora AC, Liberman UA (2004) Ten years' experience with alendronate for osteoporosis in post menopausal women. N Engl J Med 350:1189-1199

21. Chavassieux PM, Arlot ME, Reda C, Wei L, Yates AJ, Meunier PJ (1997) Histomorphometric assessment of the long-term effects of alendronate on bone quality and remodelling in patients with osteoporosis. J Clin Invest 100:1475-1480

22. Black DM, Schwartz AV, Ensrud KE, Cauley JA, Levis S, Quandt SA, Satterfield S, Wallace RB, Bauer DC, Palermo L, Wehren LE, Lombardi A, Santora AC, Cummings SR (2006) Effects of continuing or stopping alendronate after 5 years of treatment: the Fracture Intervention Trial Long-term Extension (FLEX): a randomized trial. JAMA 296:2927-2938

23. van der Poest Clement E, van Engeland M, Ader H, Roos JC, Patka P, Lips P (2002) Alendronate in the prevention of bone loss after a fracture of the lower leg. J Bone Miner Res 17:2247-2255

24. Van der Poest Clement E, Patka P, Vandormael K, Haarman H, Lips $P$ (2000) The effect of alendronate on bone mass after distal forearm fracture. J Bone Miner Res 15:586-593

25. Boskey AL, Spevak L, Weinstein RS (2008) Spectroscopic markers of bone quality in alendronate-treated postmenopausal women. Osteoporos Int 20:793-800

26. Guy JA, Shea M, Peter CP, Morrissey R, Hayes WC (1993) Continuous alendronate treatment throughout growth, maturation, and aging in the rat results in increases in bone mass and mechanical properties. Calcif Tissue Int 53:283-288

27. Seidlova-Wuttke D, Hesse O, Jarry H, Christoffel V, Spengler B, Becker T, Wuttke W (2003) Evidence for selective estrogen receptor modulator activity in a black cohosh (Cimifuga racemosa) extract: comparison with estradiol-17beta. Eur J Endocrinol 149:351-362

28. Wronski TJ, Lowry PL, Walsh CC, Ignaszewski LA (1985) Skeletal alterations in ovariectomized rats. Calcif Tiss Int 37:324-328

29. Stuermer EK, Sehmisch S, Rack T, Wenda E, Seidlova-Wuttke D, Tezval M, Wuttke W, Frosch KH, Stuermer KM (2009) Estrogen and raloxifene improve metaphyseal fracture healing in the early phase of osteoporosis. A new fracture-healing model at the tibia in rat. Lang Arch Surg (in press)

30. Rahn BA (1976) The fluorochrome sequence labeling of the bone. Nova Acta Leopold 44:249-255

31. Stürmer EK, Seidlova-Wuttke D, Sehmisch S, Rack T, Wille J, Frosch KH, Wuttke W, Stürmer KM (2006) Standardized bending and breaking test for the normal and osteoporotic metaphyseal tibias of the rat: effect of estradiol, testosterone, and raloxifene. J Bone Miner Res 21:89-96

32. Schenk RK (1965) The histological preparation of undecalcified bone. Acta Anat 60:3-19

33. Parfitt AM, Drezner MK, Glorieux FH, Kanis JA, Malluche H, Meunier PJ, Ott SM, Recker RR (1987) Bone histomorphometry: standardization of nomenclature, symbols, and units. Report of the ASBMR histomorphometry nomenclature committee. J Bone Miner Res 2:595-610

34. Nikolaou VS, Efstathopoulos N, Kontakis G, Kanakaris NK, Giannoudis PV (2009) The influence of osteoporosis in femoral fracture healing time. Injury 40:663-668

35. Bolander ME, Sabbagh R, Jeng C (1992) Estrogen treatment during fracture repair strengthens healing callus in an osteoporotic model. Trans Orthop Res Soc 17:138

36. Schmidmaier G, Wildemann B, Bail H, Lucke M, Fuchs T, Stemberger A, Flyvberg A, Haas NP, Raschke M (2001) Local application of growth factors insulin-like growth factor-1 and transforming growth factor- $\beta$ from a biodegradable poly (d, 1lactide) coating of osteosynthetic implants accelerated fracture healing in rats. Bone 28:341-350

37. Aspenberg P, Wermelin K, Tengwall P, Fahlgren A (2008) Additive effects of PTH and bisphoshonates on the bone healing response to metaphyseal implants in rats. Acta Orthop 79:111-115

38. Morgan EF, Mason ZD, Bishop G, Davis AD, Wigner NA, Gerstenfeld LC, Einhorn TA (2008) Combined effects of recombinant human BMP-7 (rhBMP-7) and parathyroid hormone (1-34) in metaphyseal bone healing. Bone 43:1031-1038

39. Tsiridis E, Morgan EF, Bancroft JM, Song M, Kain M, Gerstenfeld L, Einhorn TA, Bouxsein ML, Tornetta P 3rd (2007) Effects of OP-1 and PTH in a new experimental model for the study of metaphyseal bone healing. J Orthop Res 25:1193-1203

40. Manabe T, Mori S, Mashiba T, Cao Y, Kaji Y, Iwata K, Komatsubara S, Yamamoto T, Seki A, Norimatsu H (2009) Eel calcitonin (elcatonin) suppressed callus remodeling but did not interfere with fracture healing in the femoral fracture model of cynomolgus monkeys. J Bone Miner Metab 27:295-302

41. Nancollas GH, Tang R, Phipps RJ, Henneman Z, Guide S, Wu W, Mangood A, Russell RG, Ebetino FH (2006) Novel insights into actions of bisphosphonates on bone: differences in interactions with hydroxyapatite. Bone 38:617-627

42. Cao YP, Mori S, Mashiba T (2007) Fracture callus under antiresorptive agent treatment evaluated by pQCT. In: Advanced bioimaging technologies in assessment of the quality of bone and scaffold materials techniques and applications. Springer, London, pp 553-566

43. Kolios L, Sehmisch S, Daub F, Rack T, Tezval M, Stuermer KM, Stuermer EK (2009) Equol but not Genistein improves fracture healing in severe experimental osteoporotic bone in rats. Planta Med 75:459-465 